Original Research Article

\title{
Assessment of prescription writing practices in a government tertiary care hospital in Haryana by using WHO prescribing indicators
}

\author{
Kamaldeep Singh, Garima Bhutani*, Seema Rani, Rahul Saini
}

Department of Pharmacology, BPS GMC (W), Khanpur Kalan, Sonepat, Haryana, India

Received: 17 July 2019

Revised: 17 August 2019

Accepted: 19 August 2019

*Correspondence to:

Dr. Garima Bhutani,

Email: garimaahuja2010

@yahoo.com

Copyright: (C) the author(s), publisher and licensee Medip Academy. This is an openaccess article distributed under the terms of the Creative Commons Attribution NonCommercial License, which permits unrestricted noncommercial use, distribution, and reproduction in any medium, provided the original work is properly cited.

\begin{abstract}
Background: Writing a prescription is a combination of science and art. Good quality prescriptions are a sign of prescriber's expertise. World Health Organization has defined certain parameters to promote rational drug use in all countries. This study was designed to assess the prescription writing practices in a government tertiary care hospital in Haryana by using WHO prescribing indicators.
\end{abstract}

Methods: A total of 2155 prescriptions were evaluated. Each prescription was evaluated for average number of drugs prescribed per patient per encounter, percentage of drugs prescribed by generic name, percentage of encounters with an antibiotic prescribed, percentage of encounters with an injection prescribed and percentage of medicines from Essential drug list prescribed. These indicators help us to check polypharmacy, practice of prescribing drugs by brand names, antibiotic overuse, preference of injectables and non-adherence to Essential drug list.

Results: The average number of drugs prescribed per patient per encounter was calculated to be $3.25 \pm 0.24$. The percentage of medicines prescribed by generic names was $35.89 \%$. Percentage of encounters with an antibiotic prescribed was $48.21 \%$ and with an injection prescribed was $1.85 \%$. The percentage of medicines form NLEM was $76.36 \%$.

Conclusions: The values of WHO prescribing indicators obtained from this study show that there are some areas where the prescribers need to improve their prescribing practices.

Keywords: Essential drug list, Generic names, Prescription, WHO prescribing indicators

\section{INTRODUCTION}

A prescription is a written order by a physician to a pharmacist to dispense medicines to the patient. ${ }^{1}$ Writing a prescription is a combination of science and art. Good quality prescriptions are a sign of prescriber's expertise. For a patient, a good quality and balanced prescription means more beneficial effects, lesser adverse effects and lower financial burden. So, to increase patients' safety and patients' compliance we need to maintain the good quality of the prescriptions. For this, we must first evaluate the prescription writing practices and the quality of the prescriptions. There are many tools available with which we can perform this task, for e.g., WHO prescribing indicators, WHO patient care indicators, WHO health facility indicators, Prescription Quality index (PQI) etc. ${ }^{2,3}$ Further we can evaluate the prescriptions by designing a proforma based on the current medical practices and according to the need of the study.

World Health Organization has defined certain parameters to promote rational drug use in all countries. They are called as prescribing indicators. The basic idea of using these parameters is to keep a check on irrational prescribing and to promote rational use of drugs. By calculating these indicators comparisons can be drawn between different countries, different states of the same country, different hospitals of the same district or even different departments of the same hospital. A comparison can also be made between government and private hospitals. 
These parameters provide data to check polypharmacy i.e., simultaneously prescribing many drugs. Inadvertent polypharmacy leads to drug-drug interactions, which harms the patient instead of benefitting. Tendency to prescribe drugs by brand names is also checked. Prescribing the drugs by generic names decreases the overall expenditure of the patient. Antibiotic overuse can lead to development of antibiotic resistance. Use of injections where oral dosage forms can be used is not only expensive but also increases the cost of the prescribed drugs. The prescribing indicators given by WHO also help us to check whether the prescribers are adhering to the essential drug list or not. In this study we have used WHO prescribing indicators to analyze the prescriptions. We believe that this study will be of help in improving the prescription standards of the doctors.

\section{METHODS}

The present study was designed with the aim of analyzing the prescription patterns by using the cross-sectional observational approach. This study was conducted at the Hospital of Bhagat Phool Singh Government Medical College for Women, Khanpur Kalan, Sonepat. The study was conducted over a period of one year (February 2018 to January 2019). Prescriptions were collected from only those patients who were attending the outpatient department and a written informed consent was taken from them before taking prescriptions. The prescriptions of patients attending emergency department and receiving treatment on indoor basis were excluded from the study. Photocopies of the prescriptions were taken and kept for analysis and original prescriptions were returned to the patients. A total of 2155 prescriptions were evaluated.

Each prescription was evaluated by using WHO prescribing indicators and the data for all the prescriptions was entered into MS Excel (version 1907) software. The calculations were done using this software only. They were calculated as follows:
- Average number of drugs prescribed per patient per encounter: It was calculated by dividing the total number of drugs prescribed in all the prescriptions collectively by the total number of prescriptions surveyed.

- Percentage of drugs prescribed by generic name: It was calculated by dividing the number of drugs prescribed by generic name by the total number of drugs prescribed, multiplied by hundred.

- Percentage of encounters with an antibiotic prescribed: It was calculated by dividing the number of prescriptions in which antibiotics were prescribed by total number of prescriptions, multiplied by hundred.

- Percentage of encounters with an injection prescribed: It was calculated by dividing the number of prescriptions in which injections were prescribed by total number of prescriptions, multiplied by hundred.

- Percentage of medicines from Essential drug list prescribed: It was calculated by dividing the number of drugs prescribed from the NLEM of India by the total number of drugs prescribed, multiplied by hundred.

The values of the WHO prescribing indicators obtained from this study were then compared to the recommended optimal values given by $\mathrm{WHO}{ }^{4}$

\section{RESULTS}

A total of 6998 drugs were found to be prescribed in the 2155 prescriptions that were analysed. The average number of drugs prescribed per patient per encounter was calculated to be $3.25 \pm 0.24$. The percentage of medicines prescribed by generic names was $35.89 \%$. Percentage of encounters with an antibiotic prescribed was $48.21 \%$ and with an injection prescribed was $1.85 \%$. The percentage of medicines form NLEM was $76.36 \%$. The results of the study are shown in the Table 1 and Figures 1 to 4 .

Table 1: WHO prescribing indicators.

\begin{tabular}{|lll|}
\hline Indicator & Calculation & \multicolumn{1}{l|}{ Value } \\
\hline $\begin{array}{l}\text { Average number of drugs prescribed per patient per } \\
\text { encounter }\end{array}$ & $6998 / 2155$ & $\begin{array}{l}3.25 \pm 0.24 \\
(\mathrm{Mean} \pm \mathrm{SEM})\end{array}$ \\
\hline Percentage of medicines prescribed by generic name & $(2512 / 6998) \times 100$ & $35.89 \%$ \\
\hline Percentage of encounters with an antibiotic prescribed & $(1039 / 2155) \times 100$ & $48.21 \%$ \\
\hline Percentage of encounters with an injection prescribed & $(40 / 2155) \times 100$ & $1.85 \%$ \\
\hline Percentage of medicines from Essential drug list prescribed & $(5344 / 6998) \times 100$ & $76.36 \%$ \\
\hline
\end{tabular}

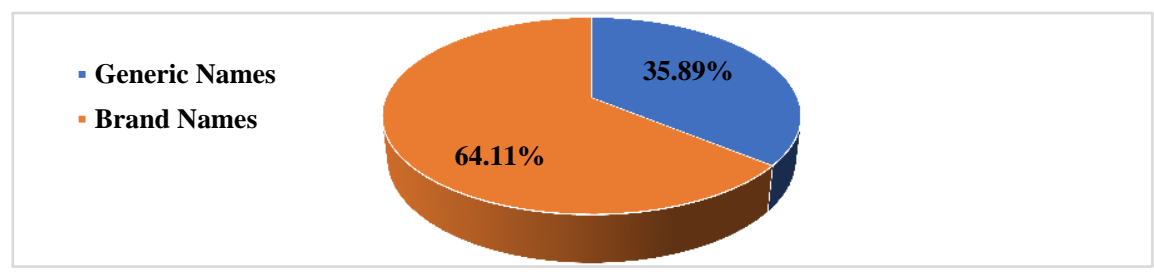

Figure 1: Percentage of medicines prescribed by generic and brand names. 


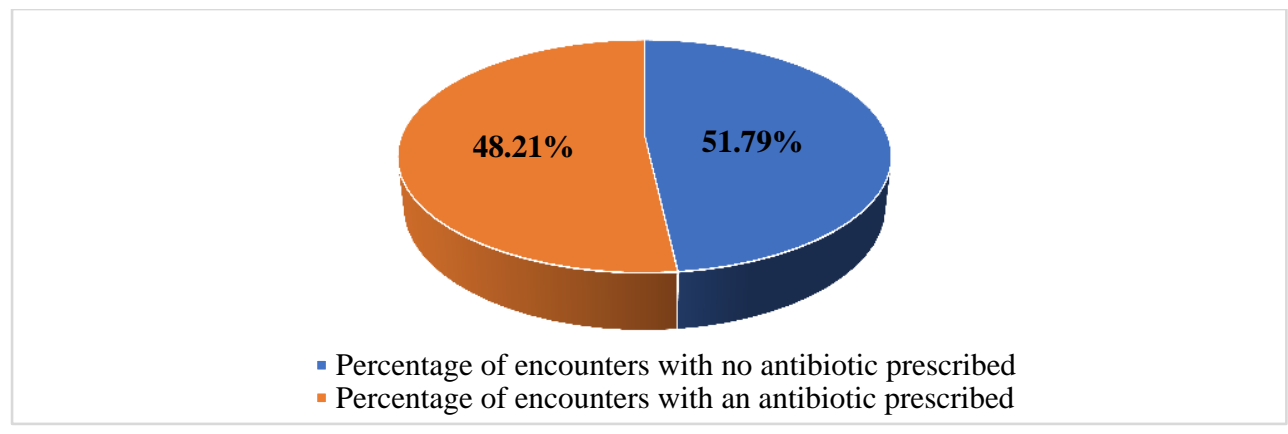

Figure 2: Percentage of encounters with an antibiotic prescribed.

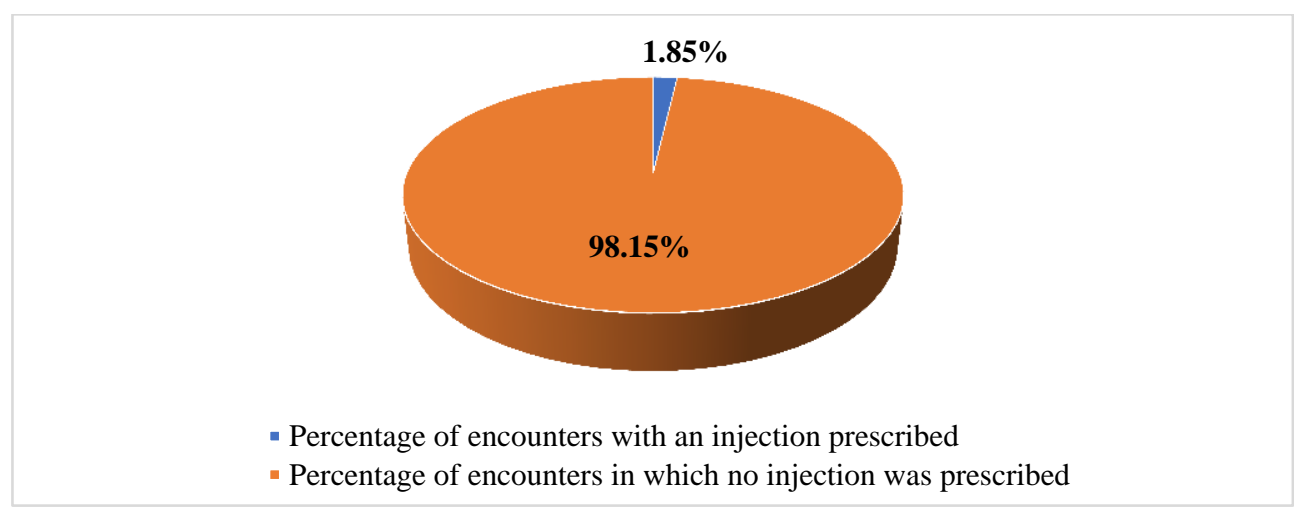

Figure 3: Percentage of encounters with an injection prescribed.

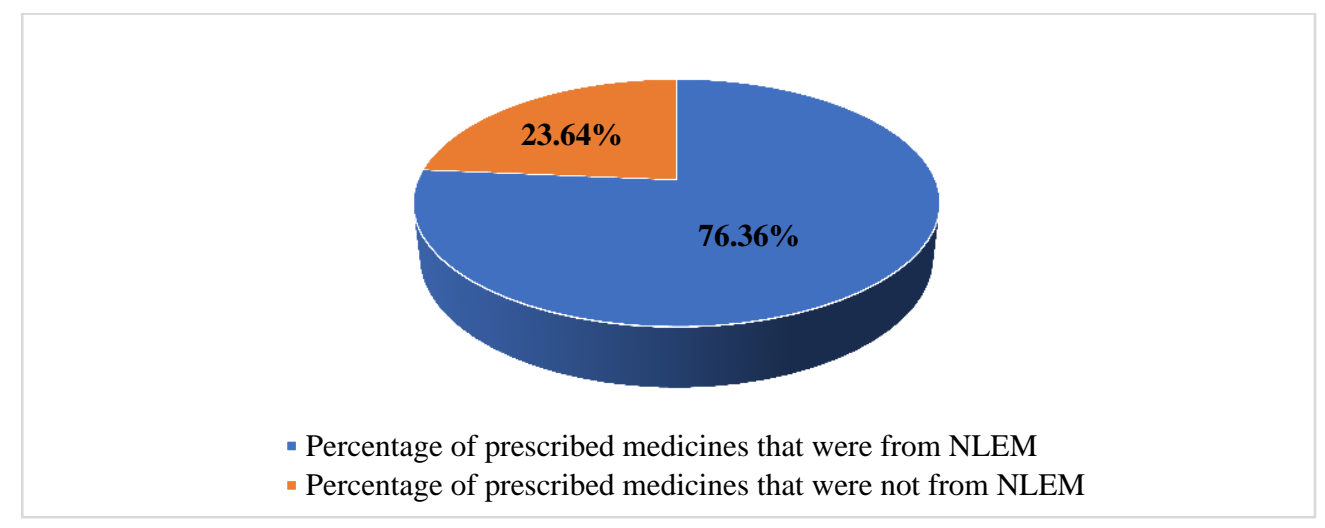

Figure 4: Percentage of prescribed medicines that were from NLEM.

\section{DISCUSSION}

In our study, the average number of drugs prescribed per patient per encounter was calculated to be $3.25 \pm 0.24$. This value is more than the WHO optimal value which is less than two $(<2){ }^{4}$ In their study, Potharaju et al calculated that on an average 3.1 drugs were prescribed per prescription, which is almost similar to our study. While in other studies by Chetia et al, Sisay et al and Bilal et al considerably lower values were obtained, which were $2.37,2.34$ and 2.2 , respectively. ${ }^{6-8}$ Lesser values of average number of drugs prescribed imply less chances of drug interactions and more patient safety and better patient compliance. In our study, the percentage of medicines prescribed by generic names was $35.89 \%$ while according to $\mathrm{WHO}$, the optimal percentage of drugs prescribed by generic names should be $100 \%{ }^{4}$ Bilal et al and Sisay et al calculated this value to be $97 \%$ and $90.61 \%$, both of which are much better than our value and are closer to the WHO recommended value. ${ }^{7,8}$ While a study by Potharaju et al, it was observed that percentage of drugs prescribed by generic names was $60 \% .^{5}$ In their study, Chetia et al found this percentage to be $3.36 \%$, which is much lower than our value and remarkably lower than the WHO recommendations. ${ }^{6}$ Drugs when prescribed by generic names impose less burden on the patients. In our study, we found that the percentage of encounters with an antibiotic prescribed was $48.21 \%$. The WHO recommended optimal value for this is less than $30 \%{ }^{4}$ This value has been recommended 
by WHO keeping in mind the inherent risks of antibiotic overuse, most serious of which is antibiotic resistance. Chetia et al found similar results in their study, showing this value to be $42.38 \% .^{8}$ While Bilal et al and Sisay et al, found respectively that in $82.5 \%$ and $57.87 \%$ of the prescriptions one or more antibiotics were prescribed. ${ }^{7,8}$ Both of these values were greater than value obtained in our study. While, in their study, Potharaju et al obtained this value to be $35 \%$ which was lesser and better than value of our study. ${ }^{5}$ We found that the percentage of encounters where an injection was prescribed was $1.85 \%$. The optimal value for this is less than $20 \%$. $^{4}$ The value for this prescribing indicator was calculated to be $11.41 \%$ by Chetia et al, $11.2 \%$ by Bilal et al, $10.9 \%$ by Sisay et al and $25 \%$ by Potharaju et al. ${ }^{5-8}$ Hence, the results of our study are better than these studies in terms of this parameter because more use of injectable formulations would lead not only to patient discomfort but also increased chances of infections. In our study, the percentage of medicines from NLEM was $76.36 \%$. As per WHO, optimally all the prescribed drugs (i.e., $100 \%$ of the drugs) should be from the list of essential drugs. ${ }^{4}$ While, Bilal et al calculated the percentage of drugs prescribed from essential drug list to be $92 \%$, which was much better than our study. ${ }^{8}$ In another study, Potharaju et al, this value was found to be $46 \%$ which was markedly lower than our calculated value. ${ }^{5}$

All of these values obtained in our study for WHO prescribing indicators show that the prescribers do not adhere to the WHO recommendations regarding prescribing. This may be due to lack of their knowledge regarding the same. It implies that some steps must be taken to develop good prescribing practices in doctors. During graduation and post-graduation more emphasis should be laid on rational prescription writing along-with supervised practical teaching programmes. Faculty development programmes and CMEs should be held on periodical basis for consultants and faculty members so as to improve their prescription writing skills. Making the NLEM or state EML available and displayed at various OPDs and wards can also help improve the tendency of the doctors to prescribe the drugs from within this list.

\section{CONCLUSION}

The values of the WHO prescribing indicators were not fully in agreement with the optimal reference values as given by WHO, except percentage of encounters with an injection prescribed. The average number of drugs prescribed per patient was almost in concordance with WHO recommended values, but the prescribing doctors largely need to correct their tendency to prescribe drugs by their brand names. Rational use of antibiotics also needs to be promoted. Prescribing drugs from NLEM should also be encouraged.

\section{Funding: No funding sources}

Conflict of interest: None declared

Ethical approval: The study was approved by the Institutional Ethics Committee

\section{REFERENCES}

1. Badyal D. Practical Manual of Pharmacology. 1st edition. New Delhi: Jaypee Brothers Medical Publishers (P) Ltd; 2008: 112-157.

2. World Health Organisation. Rational use of Medicines 2010. Available from: http://www.who. int/medicines/areas/rational_use/en/index.html. Accessed 15 July 2019.

3. Hassan NB, Ismail HC, Naing L, Conroy RM, Rahman AR. Development and validation of a new Prescription Quality Index. Br J Clin Pharmacol. 2009;70(4):500-13.

4. World Health Organization. Guide to drug financing mechanisms 1998. Available from: http://apps.who. int/medicinedocs/en/d/Jh2928e/\#Jh2928e. Accessed 15 July 2019.

5. Potharaju HR, Kabra SG. Prescription audit of outpatient attendees of secondary level government hospitals in Maharashtra. Indian $\mathrm{J}$ Pharmacol. 2011;43(2):150-6.

6. Chetia D, Nada N, Rudrapal M. Study on the use of medicines in some selected health care facilities of Arunachal Pradesh. Asian J Pharm Clin Res. 2011;4(3):80-1.

7. Sisay M, Mengistu G, Molla B, Amare F, Gabriel T. Evaluation of rational drug use based on World Health Organization core drug use indicators in selected public hospitals of eastern Ethiopia: a cross sectional study. BMC Health Serv Res. 2017;17(161):1-9.

8. Bilal AI, Osman ED, Mulugeta A. Assessment of medicines use pattern using World Health Organization's Prescribing, Patient Care and Health facility indicators in selected health facilities in eastern Ethiopia. BMC Health Serv Res. 2016;16(144):1-8.

Cite this article as: Singh K, Bhutani G, Rani S, Saini R. Assessment of prescription writing practices in a government tertiary care hospital in Haryana by using WHO prescribing indicators. Int J Basic Clin Pharmacol 2019;8:2145-8. 